\title{
How to make Mandela smile: being methodical, motivated and meaningful
}

\author{
Jon Patricios (i) ,' Siyabonga Kunene ${ }^{2,3}$
}

\begin{abstract}
Sport can create hope where once there was only despair. It is more powerful than governments in breaking down racial barriers. It laughs in the face of all types of discrimination $^{1}$
\end{abstract}

These telling words of Nelson Mandela allude to the ubiquitous and global phenomenon of discrimination, the prevalent societal despair we have all witnessed in the recent past, and the hope we all wish to foster. They also remind us of the honour of being involved in the world of sport and exercise medicine (SEM).

The themes of this South Africanguided edition of BJSM intentionally draw on current and critical issues aligned with Mandela's words, and continues the South African Sports Medicine Association's commitment to accomplishing strength through diversity. We feature papers highlighting marginalised communities in SEM, while other high-calibre articles cover the topics of methodology, concussion and COVID-19. We align with the BJSM editorial team's commitment to creating awareness of issues around equity, diversity and inclusion and we aim to leave clinicians with some clear guidance, clarity and motivation.

\section{MARGINALISATION IN SEM}

SEM is far from an equitable space, resulting in athletes and colleagues alike being moved to the fringes of our profession, compromising their access to rights and resources. A cohort that can quite rightfully feel aggrieved is the Para athlete community and those that care for them. Dr Nick Webborn, OBE (@sportswiseUK) contributes to an editorial (see page 529)

\footnotetext{
${ }^{1}$ Wits Sport and Health (WiSH), School of Clinical Medicine, Faculty of Health Sciences, University of the Witwatersrand, Johannesburg-Braamfontein, South Africa

${ }^{2}$ Wits Sport and Health (WiSH), School of Therapeutic Sciences, Faculty of Health Sciences, University of the Witwatersrand, Johannesburg-Braamfontein, South Africa

${ }^{3}$ Department of Physiotherapy, School of Therapeutic Sciences, Faculty of Health Sciences, University of the Witwatersrand, Johannesburg-Braamfontein, South Africa

Correspondence to Professor Jon Patricios, Wits Sport and Health (WiSH), School of Clinical Medicine, Faculty of Health Sciences, University of the Witwatersrand, Johannesburg-Braamfontein, South Africa; jpat@mweb.co.za
}

on prioritising care for Para athletes, a harbinger to the first consensus statement on concussion care in this remarkable group of athletes, available soon Online First. The marginalisation theme is completed by papers from Professor Emmanuel Stamatakis' group on 'privileging the privileged' (see page 525) and Dr Eimear Enright's editorial on sport and therapy in young people with cerebral palsy (see page 524).

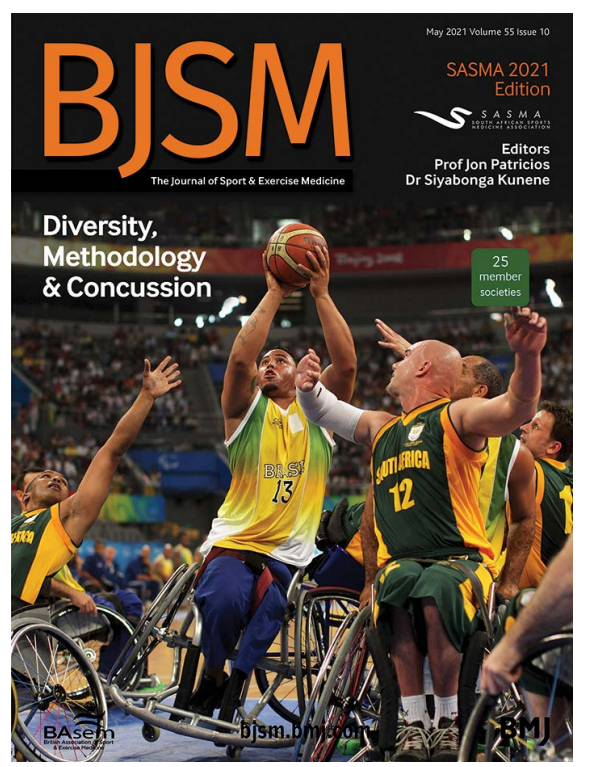

\section{METHODS MATTER ... MORE AND MORE}

Three very important contributions stress the importance of a sound methodological strategy to research and consensus. Prolific methodologist Professor Mohammed Ali Mansournia explains network metaanalyses and their importance for clinicians and researchers (see page 520), and Professor Marinus Winters leads a strong group of methodologists looking at the increasing trend of conducting living systematic reviews (see page 519). Watch this space ... the Concussion in Sport Group may go this route post-2021. Dr Ian Shrier's review of consensus processes and statements and their potential flaws sounds some warning bells-'consensus is not unanimity'. Importantly he provides some solutions for including dissenting views (see page 545).

\section{CONCUSSION AND COVID-19}

Sport-related concussion is arguably an area that has received more SEM press than any other in the last decade. BJSM continues its role in knowledge translation. Leading neuropsychologist Dr Ruben Echemendia and his team publish a twopart feature on the use of the SCAT5 in the NHL (see page 550 and see page 557), with additional perspectives from World Rugby CMO Dr Ėanna Falvey (see page 527) and a medicolegal context provided by Dr Michael Turner (see page 539). On a very positive note, BJSM digital and social mediaguru@SteffanGriffin provides infographic and digital resources highlighting his $\mathrm{PhD}$ work on the health benefits of Rugby (see page 568). COVID-19 and sport was thoroughly covered in an earlier BJSM edition edited by Sports Medicine Australia's Dr Liam West, but here an inter-association, multi-sport group led by $\mathrm{Dr}$ Lisa Hodgson provides guidance on pitch side care and personal protective equipment (see page 531).

\section{PROUDLY SOUTH AFRICAN: A QUESTION OF COLOUR}

As a tribute to the Para athlete, South African Paralympian basketballer Richard Nortje features on this editorial page. Several included contributions spanning the topics of the Para athlete, COVID19, and marginalisation have a South African flavour. These include Dr Glen Hageman's excellent infographic on successfully hosting a mass event during a pandemic (see page 570). There is no doubt that Nelson Mandela would have smiled reading Dr Phathokuhle Cele Zondi's editorial 'A question of colour ...' (see page 526). Together with the University of Washington's Dr Ashley Austin, this leading South African voice for equality and inclusion (@phatho_z) highlights the deplorable under-representation of black SEM clinicians and researchers, warns against the covert nature of such racism, and calls for an actionable game plan for greater diversity in SEM.

\section{SPOTLIGHT ON}

This issue is honoured to feature the first BJSM 'Service Spotlight', aimed at highlighting the work of individuals and groups whose community service has advanced safe and healthier sport particularly in marginalised communities and vulnerable populations. These stories are meant to inspire and the feature on this edition's coeditor hopefully does exactly that (see page 566). Due to limited rehabilitation services in marginalised communities, 
poorer athletes train and compete with injuries that limit performance and compromise quality of life. In a South African model that utilises 'task-shifting', the inaccessibility of socioeconomically poor communities to SEM professionals is addressed. Rehabilitation services are taken to the communities where athletes reside (community-based rehabilitation) and made affordable at a low/no cost. This is made possible if relevant stakeholders (SEM clinicians, sports associations/federations, government sports and health departments and private agencies) identify and prioritise these communities, shifting the focus from personal or organisational gains and profits to communityorientated service. To address a scarcity of relevant sports clinician service providers, a transdisciplinary rehabilitation model is proposed to ensure that athletes receive appropriate rehabilitation. Less skilled healthcare personnel (eg, community healthcare workers, therapist assistants, university medical students), coaches and trainers are upskilled in the implementation of injury prevention and rehabilitation programmes in the needy communities. Mr Mandela's smile has just turned into a wide grin!

\section{COMMITMENT}

This South African-led edition of BJSM hopes to embody the new vision of BJSM as outlined by the Editor-in-Chief. A high quality, clinically orientated, multimedia SEM journal that provides rigorously peer-reviewed articles with high impact but understands its influential role in addressing societal inequities in our field. Nelson Mandela appreciated that we cannot ignore our social context. As motivated clinicians and researchers our approach needs to be methodical but, perhaps above all, meaningful.

\section{Twitter Jon Patricios @jonpatricios}

Contributors JP conceived the design of the editorial, developed the article framework and drafted the original version of the manuscript. SK is the originator of the 'task-shifting' concept, drafted the section relevant to that, contributed to each subsection and finally reviewed and edited the entire manuscript.
Funding The authors have not declared a specific grant for this research from any funding agency in the public, commercial or not-for-profit sectors.

Competing interests JP is an editor of BJSM and receives an honorarium from $B M J$.

Patient consent for publication Not required.

Provenance and peer review Commissioned; internally peer reviewed.

(C) Author(s) (or their employer(s)) 2021. No commercial re-use. See rights and permissions. Published by BMJ.

\section{Check for updates}

To cite Patricios J, Kunene S. Br J Sports Med 2021;55:517-518.

Accepted 20 March 2021

Br J Sports Med 2021;55:517-518. doi:10.1136/bjsports-2021-104246

ORCID iD

Jon Patricios http://orcid.org/0000-0002-6829-4098

\section{REFERENCES}

1 . Available: https://www.laureus.com/news/celebratingthe-legacy-of-a-hero-on-mandela-day [Accessed 7 March 2021].

2 Patricios J. Diversity among our disciplines: let's provide differing perspectives in the interest of athlete care. $\mathrm{Br} J$ Sports Med 2020;54:561-2. 